\title{
Changing discourses in Aboriginal and Torres Strait Islander health research, 1914-2014
}

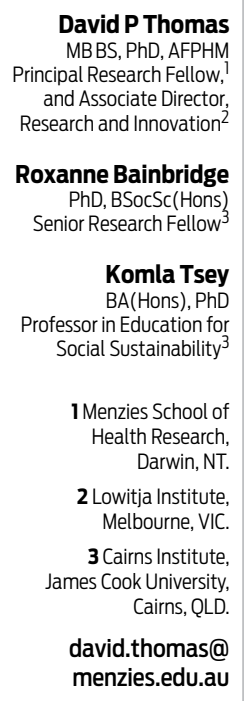

doi: 10.5694/mjal4.00114

Online first 23/06/14
he value of health research to individuals and society is indisputable. It contributes to improvements in health care and public health by providing information about disease trends, risk and protective factors, patterns of care and health care costs, developing new therapies and treatments, and assessing the effectiveness of health interventions. Aboriginal and Torres Strait Islander (respectfully, Indigenous hereafter when referenced together) health research therefore can make a critical contribution to raising the health and wellbeing of Indigenous Australians and other Australians. The degree to which health research is valuable, however, depends on its nature, quantity and quality. 1

Arabena and Moodie note that "despite all the research and the medical interventions spanning decades, improvements - where they occur - are incremental and trend up at a slower rate than for non-Indigenous Australians". ${ }^{2}$ In many reviews, concerns have been expressed about the overemphasis on descriptive research rather than research evaluating interventions in Indigenous health. ${ }^{1,3-6}$

In this centenary of the $M J A$, we describe how Indigenous health research has been influenced by colonial social ideologies and shifting discourses in Indigenous political struggles. We start our commentary with the changing nature of Indigenous health research in the early years of the Journal, ${ }^{7}$ concentrating on historical themes of most relevance to current debates. Then we discuss some important recent developments in Indigenous health research. Our narrow focus on Indigenous health research reflects similar influences on many aspects of Indigenous lives.

\section{Protecting the health of white Australia against exotic tropical infections}

Before 1950, health researchers had little regard for the health needs of Indigenous people. Indigenous health received little attention in the MJA (Box 1, Box 2) or preceding Australian medical journals, ${ }^{7}$ and the earliest articles predominantly related to tropical medicine, especially hookworm and donovanosis. This tropical health research was not only entangled with the politics of colonialism and a white Australia, but also with broader discourses of "whiteness", race degeneracy in a "new" environment, and the national Australian identity. ${ }^{8}$ While hookworm was the first disease among Indigenous people to receive sustained attention in the $M J A$, the primary focus was the protection of the health of the white population. ${ }^{9-13}$ Early hookworm campaigns concentrated on Queensland, with its larger white population, rather than the Northern Territory, where hookworm infection was common among Indigenous people but less important because it was not "a menace to white people". ${ }^{14}$ However, Indigenous people's health needs were not always ignored. In 1929, the MJA reported on the Victorian Branch of the British Medical

\begin{abstract}
Summary
Aboriginal and Torres Strait Islander people strongly assert that health research has contributed little to improving their health, in spite of its obvious potential.

The health concerns of Aboriginal and Torres Strait Islander people were largely ignored in early research published in the MJA, which reflected broader colonial history and racial discourses. This began to change with the demise of scientific racism, and changed policies and political campaigns for equal treatment of Indigenous people after the Second World War.

In response to pressure from Aboriginal and Torres Strait Islander people and organisations, in parallel to broader political struggles for Indigenous rights since the 1970s, there have been significant and measurable changes to Aboriginal and Torres Strait Islander health research. Many of these changes have been about the ethics of health research.

Increasingly, Aboriginal and Torres Strait Islander researchers, communities and organisations are now controlling and decolonising health research to better meet their needs, in collaboration with non-Indigenous researchers and research organisations.
\end{abstract}

Association's concerns about the absence of medical and nursing care for Aboriginal people in Central Australia. ${ }^{15}$

Indigenous people's access to better health care was considered less important because most Australian doctors repeatedly read and believed that Indigenous people were an inferior and primitive race whose demise was inevitable. ${ }^{7}$ Palliation was all that was required, or "smoothing the pillow of the dying race" ${ }^{\prime 7,16}$ Some took this palliation more seriously, while many used it to excuse their guilt for suffering caused by colonialism. ${ }^{16}$ This belief in the doom of the Indigenous population did create a sense of urgency for researchers to collect information about Indigenous people for science before it was too late. In 2011, the Journal noted that Indigenous health research is still too "observational and deficit-focused, with a dearth of interventional studies" and "even considered putting a moratorium on publishing the many observational studies" being submitted. ${ }^{17}$

\section{Salvaging data on a dying race for science}

Before 1950, Sir John Burton Cleland wrote one in every six articles about Indigenous health in the $M J A$, and was the most prominent doctor in salvaging Indigenous data for science. ${ }^{7}$ Professor of Pathology and Microbiology at the University of Adelaide, he joined annual anthropological expeditions to Central Australia from 1925 to 1939 to collect these data, often describing the expeditions in the $M J A{ }^{18}$ Following European research on the distribution of blood groups in different populations, ${ }^{19}$ these expeditions examined blood groups to provide precise scientific 
demarcations between races, but contradictory evidence soon could not be ignored. The failure to find exact definitions and demarcations of racial categories was one of the main reasons for the decline of scientific racism. ${ }^{8,20}$ Blood group research was the most commonly mentioned Indigenous health research topic in the MJA before 1950, discussed in 16 of 113 articles. ${ }^{7}$

After the Second World War, emerging researchers avoided explanations of their research based on race, just as determinedly as earlier researchers had avoided explanations that undermined notions of biological race. ${ }^{7}$ Culture replaced race, with researchers now collecting data about a vanishing way of life, and similarities rather than differences were emphasised. Just as earlier Indigenous health research was consistent with earlier policies of protection and biological assimilation, this research was consistent with prevailing ideas of cultural assimilation. ${ }^{7}$ The 1950 s and 1960s also saw the rise of research written by those in the NT providing health care for Aboriginal people about the issues causing most Aboriginal ill health (not just affecting white health), along with descriptions of interventions for their control. ${ }^{7}$

\section{Indigenous rights and Indigenous-driven research reform}

From 1956 to 1969, Melbourne general practitioner Barry Christophers published 25 letters in the MJA promoting the Federal Council for Aboriginal Advancement's political campaigns for equal rights for Indigenous people. These letters highlighted discriminatory laws and policies, the economic causes of health problems, and the impact of racism and the way Aboriginal people were represented in the Journal. ${ }^{21}$ But no authors were yet questioning the tradition of "a white-fellah to write about Aboriginal mob for another white-fellah"; however, that would change. ${ }^{22}$

The number of Indigenous health articles dramatically increased in the MJA from the 1970s. In 1975, the Journal published its first supplement on Aboriginal health to cope with the dramatic increase in submitted manuscripts - more than 13\% (95/709) of Indigenous health articles published from 1970 to 1999 appeared in supplements. ${ }^{7}$ In this time frame, an overwhelming affirmative vote in the referendum of 1967 resulted in amendments to the Australian Constitution to give the Commonwealth Government the mandate to implement policies for the benefit of Indigenous people. The Commonwealth assumed a greater role and investment in Indigenous health increased, albeit gradually. ${ }^{23}$ However, it was really not until after the National Aboriginal Health Strategy - the seminal document that set the agenda for Indigenous health — was endorsed in 1989 that the Commonwealth began to assert substantive policy authority. ${ }^{24}$

The 1970s saw a shift from the equal civil rights agenda of the campaign for the 1967 referendum to a focus on different Indigenous rights as part of a global movement of Indigenous self-determination. The first Aboriginal community controlled health service (ACCHS) was established in Redfern in $1971 .{ }^{24}$ Now there are 140 ACCHSs, and they have been central in the drive for a new phase in Indigenous health research; this is reflected in similar
1 Indigenous health articles published in the MJA, 1914-19997

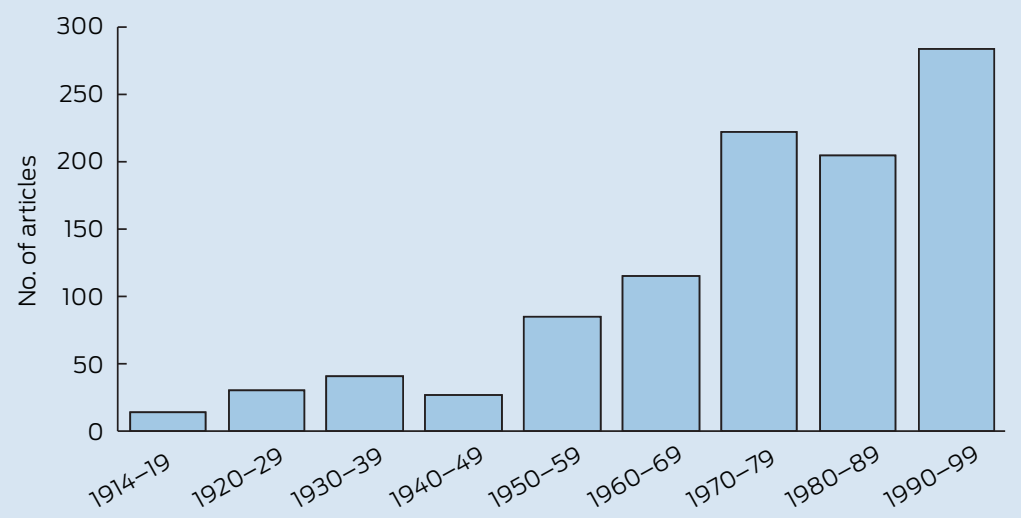

2 Indigenous health articles as a proportion of total MJA pages, 1914-19997*

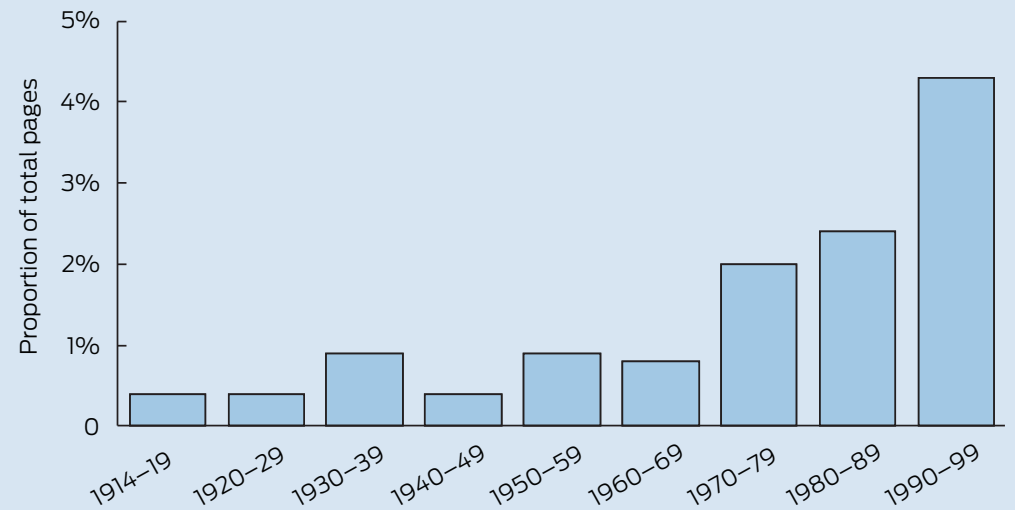

*Excludes the 99 (of a total 1022) Indigenous health articles published in supplements (of these, 95 were published between 1974 and 1986, including 21 in 1975).

changes in other areas of Indigenous politics and social policy.

By the 1990s, articles on Indigenous health accounted for more than $4 \%$ of all pages of the MJA (Box 2). ${ }^{7}$ At the same time, Indigenous scholars such as Lester-Irabinna Rigney began challenging dominant knowledge systems in their writing on Indigenous epistemologies and articulated their own research agendas and methods. ${ }^{25} \mathrm{~A}$ global Indigenous reform agenda developed, which aimed to decolonise and dismantle Western research practices by asserting an Indigenous perspective on research and ensuring that benefits flowed from research to Indigenous people, were in partnership with Indigenous people, and were driven by Indigenous people's agendas. ${ }^{25-27}$

\section{Ethics and collaborative approaches to Indigenous health research}

During the 1990s, in response to pressure from Indigenous academics, organisations and communities, Indigenous health research became positioned in an ethical framework. ${ }^{28}$ Indigenous knowledge and aspirations for research were explicitly acknowledged. Ethical guidelines for Indigenous health research were enshrined in the policies of research and funding institutions. ${ }^{28}$ In 1991, the 
National Health and Medical Research Council (NHMRC) introduced its Guidelines on ethical matters in Aboriginal and Torres Strait Islander health research, which were replaced by Values and ethics (2003) ${ }^{29}$ and Keeping research on track (2006). ${ }^{30}$ The first two documents articulated a set of ethics for Indigenous research, while the third espoused guidelines to assist Indigenous communities to engage in research.

Despite these changes, the relationship between researchers and Indigenous organisations and community leaders remained volatile. Trust was often non-existent, and there were very few meaningful conversations between parties. Indigenous people argued that they had been researched to death with little benefit, 27,31 which they contrasted with the benefits accruing to non-Indigenous researchers through degrees and career advancements. To ameliorate these tensions, in 1997, the Cooperative Research Centre for Aboriginal and Tropical Health (CRCATH) was developed to encourage researchers and Indigenous community leaders and organisations to work more collaboratively in their pursuit of improving Indigenous health outcomes. ${ }^{31}$

The CRCATH became the Cooperative Research Centre for Aboriginal and Torres Strait Islander Health and then, since 2010, the Lowitja Institute - Australia's only Indigenous-controlled health research organisation. ${ }^{2}$ All three organisations have had a particular focus on collaboration and knowledge exchange and ensuring that research is translated into improved services and improved health for Indigenous people. ${ }^{2}$ When she opened the second Congress Lowitja in Melbourne on 14 November 2012, Pat Anderson, chairperson of the Lowitja Institute, reflected on the many changes since 1997. She recalled that at the first CRCATH planning workshop in Darwin in 1997, researchers were in one corner of the room and Indigenous people and other service providers were in the other, and she needed to facilitate discussion between the groups. By the afternoon of that day, a few of the researchers had left; however, many continue to be involved today. Now she sees many Indigenous and nonIndigenous people - researchers, service providers and community members - sharing ideas and information about how to improve Indigenous health.

\section{Recent changes designed to support Indigenous research}

Since 2002, the NHMRC has committed to spend at least $5 \%$ of its funding on Indigenous research. ${ }^{32}$ NHMRC funding for Indigenous health increased from $\$ 4$ million (2.5\% of the total) in 2000 to $\$ 48$ million (almost 6\%) in $2012 .{ }^{33}$ The NHMRC has changed processes for those applying to undertake Indigenous health research, including the assessment of applications by Indigenous researchers and the Indigenous Grant Review Panel. Its road map reports in $2002^{34}$ and $2010^{35}$ have outlined frameworks to improve Indigenous health through research. Most previous research had been concentrated on Indigenous people in rural and remote northern and central Australia, and the first road map included recommendations for more research in urban areas. Both road maps emphasised the importance of increasing the involvement of Indigenous researchers.

The most successful NHMRC contribution to increasing the numbers of Indigenous people as researchers was support provided by its population health capacitybuilding grants. ${ }^{36}$ These grants were introduced in response to a review of Australian public health research and were designed to strengthen research workforce capacity. Ten grants were awarded to Indigenous researchers. ${ }^{37}$ For example, James Cook University's Building Indigenous Research Capacity grant (2007) saw support for 19 Indigenous research scholars and, by 2013, for each NHMRC dollar invested in the project, Indigenous researchers generated three in grant, research and scholarship funding. ${ }^{38}$ To date, there have been one successful Australian Research Council Fellowship, four PhD and three Masters graduations, and 10 continuing enrolments in higher degree research programs. ${ }^{38}$ Expansion of the Indigenous workforce in health research is also being seen in other areas of research. In 2012, the National Indigenous Research and Knowledges Network, funded by the Australian Research Council, was established. It aims to "provide a platform for new Indigenous multi-disciplinary research and the establishment of a critical mass of multi-disciplinary, qualified Indigenous researchers to meet the compelling research needs of our communities". ${ }^{39}$

In 2013, the Lowitja Institute conducted Indigenous health research futures thinking workshops across Australia. They considered what research might be needed to enable Indigenous health and wellness, the capacity required and how it should be conducted. Workshop participants were still repeating earlier concerns about the ethics of research, including how it is done and whether it benefits Indigenous people ${ }^{40}$ which suggests a need for future research to assess research impact and benefit for Indigenous people.

\section{Conclusion}

Despite achievements, the concern that Indigenous people have been over-researched without corresponding improvements in their health remains. ${ }^{40}$ Most commonly, the solution has concentrated on calls to shift from an overemphasis on descriptive research to more intervention research. The recent and more distant history of Indigenous health research suggest even greater opportunities with the increased decolonising of research processes. These changes in research processes reflect broader historical and political changes. The health concerns of Indigenous people are now less likely to be ignored. Increasingly, Indigenous people are now controlling research that is sensitive to their distinctive identities, values and history. Within the Lowitja Institute, some have shifted the research lens from Indigenous people to usefully describing how Indigenous health organisations are funded, ${ }^{41}$ and moved the focus from just funding more research to also funding knowledge exchange that ensures that the results from research are used to improve Indigenous health practice and wellbeing. ${ }^{42}$ Research is more likely to realise its potential to improve Indigenous health with greater involvement and funding of Indigenous people as researchers, improved research processes and ethical 
frameworks to guide and keep accountable researchers and research organisations, and development of methods to assess research impact and benefit for Indigenous people.

Acknowledgements: David Thomas is supported by a National Heart Foundation Fellowship and completed much of the early historical research for this article while supported by an NHMRC scholarship. Roxanne Bainbridge is supported by an Australian Research Council Discovery Indigenous Award.

Competing interests: No relevant disclosures.

Provenance: Commissioned; externally peer reviewed.

1 Sanson-Fisher RW, Campbell EM, Perkins JJ, et al. Indigenous health research: a critical review of outputs over time. Med J Aust 2006; 184: 502-505.

2 Arabena K, Moodie D. The Lowitja Institute: building a national strategic research agenda to improve the health of Aboriginal and Torres Strait Islander peoples. Med J Aust 2011; 194: 532-534.

3 Paul CL, Sanson-Fisher R, Stewart J, Anderson AE. Being sorry is not enough: the sorry state of the evidence base for improving the health of Indigenous populations. Am J Prev Med 2010; 38: 566-568.

4 McCalman J, Bainbridge R, Clifford A, Tsey K. A systematic literature search of cultural competence indicators and interventions targeting Indigenous peoples in Australia, New Zealand, United States and Canada. Sydney: Sax Institute for the Mental Health Drug and Alcohol Office, NSW Ministry of Health, 2013.

5 McCalman J, Tsey K, Clifford A, et al. Applying what works: a systematic search of the transfer and implementation of promising Indigenous Australian health services and programs. BMC Public Health 2012; 12: 600.

6 Clifford AC, Doran CM, Tsey K. A systematic review of suicide prevention interventions targeting indigenous peoples in Australia, United States, Canada and New Zealand. BMC Public Health 2013; 13: 463.

7 Thomas DP. Reading doctors' writing: race, politics and power in Indigenous health research, 1870-1969. Canberra: Aboriginal Studies Press, 2004.

8 Anderson W. The cultivation of whiteness: science, health and racial destiny in Australia. Melbourne: Melbourne University Press, 2002.

9 Waite JH. The Queensland hookworm campaign (first progress report, covering period April 17 to December 1, 1918). Med J Aust 1918; 2: 505-510.

10 Sawyer WA. Hookworm in Australia. Med J Aust 1921; 1: 148-150.

11 Lambert SM. Intestinal parasites in North Queensland. Med J Aust 1921; 1: 332-335.

12 Sweet WC. The intestinal parasites of man in Australia and its dependencies as found by the Australian hookworm campaign. Med J Aust 1924; 1 : 405-407.

13 Sweet WC. The activities of the Australian hookworm campaign. Med J Aust 1924; 1 Suppl: 319-324.

14 Gillespie J. The Rockefeller Foundation, the Hookworm Campaign and a national health policy in Australia, 1911-1930. In: MacLeod R, Denoon D, editors. Health and healing in tropical Australia and Papua New Guinea. Townsville: James Cook University, 1991: 64-87.

15 Anonymous. The medical care of Natives in Central Australia. Med J Aust 1929; 2: 588.

16 McGregor R. Imagined destinies: Aboriginal Australians and the doomed race theory, 1880-1939. Melbourne: Melbourne University Press, 1997.

17 Armstrong RM. Questions and answers in Indigenous health. Med J Aust 2011; 194: 491.

18 Jones PG. South Australian anthropological history: the Board for Anthropological Research and its early expeditions. Records of the South Australian Museum 1987; 20: 71-92.

19 Hirschfeld L, Hirschfeld H. Serological differences between the blood of different races: the result of researches on the Macedonian Front. Lancet 1919; 194: 675-679.

20 Barkan $\mathrm{E}$. The retreat of scientific racism: changing concepts of race in Britain and the United States between the world wars. Cambridge: Cambridge University Press, 1992.

21 Thomas DP. The upsurge of interest in Indigenous health in the 1950s and 1960s. Med J Aust 2004; 180: 521-523.

22 Anderson I. Writing for an Indigenous audience. Meanjin 1994; 53: 368-372.

23 Anderson I, Sanders W. Aboriginal health and institutional reform within Australian federalism. Canberra: Centre for Aboriginal Economic Policy Research, Australian National University, 1996.
24 Anderson IPS. Aboriginal health and welfare colonialism: 1967-2004 [PhD thesis]. Melbourne: LaTrobe University, 2006.

25 Rigney LI. Internationalization of an indigenous anticolonial cultural critique of research methodologies: a guide to indigenist research methodology and its principles. Wicazo Sa Review 1999; 14: 109-121.

26 Ermine W, Sinclair R, Jeffery B. The ethics of research involving Indigenous peoples. Saskatoon: Indigenous Peoples' Health Research Center, 2004.

27 Tuhiwai Smith L. Decolonizing methodologies: research and indigenous peoples. London, New York and Dunedin: Zed Books, Room 400 and University of Otago Press, 1999.

28 Melville J, Rankine P. Where to now? Issues in the management of Indigenous research in higher education. Issues Educ Res 2000; 10: 67-76.

29 National Health and Medical Research Council. Values and ethics: guidelines for ethical conduct in Aboriginal and Torres Strait Islander health research. Canberra: Commonwealth of Australia, 2003. http:// www.nhmrc.gov.au/files_nhmrc/publications/attachments/e52.pdf (accessed Jan 2014)

30 National Health and Medical Research Council. Keeping research on track: a guide for Aboriginal and Torres Strait Islander peoples about health research ethics. Canberra: NHMRC, 2006. http://www.nhmrc.gov. au/files_nhmrc/publications/attachments/e65.pdf (accessed Jan 2014).

31 Tsey K. Making research more relevant to the needs and aspirations of Indigenous Australians: the importance of research capacity development. Aborig Isl Health Work J 2001; 25: 19-24.

32 National Health and Medical Research Council. NHMRC Indigenous representation and other issues. Item 10.6. In: Report of the 144th Session of the NHMRC. Canberra: NHMRC, 2002: 15-20. http://www.nhmrc.gov.au/ publications/reports/sess144.htm (accessed Dec 2013).

33 National Health and Medical Research Council. NHMRC strategic plan 2013-2015. Canberra: Commonwealth of Australia, 2012. http://www. nhmrc.gov.au/_files_nhmrc/publications/attachments/nhl60_nhmrc strat_plan_201315.pdf (accessed Dec 2013).

34 Aboriginal and Torres Strait Islander Research Agenda Working Group of the National Health and Medical Research Council. The NHMRC Road Map: a strategic framework for improving Aboriginal and Torres Strait Islander health through research. Canberra: Commonwealth of Australia, 2002. http://www.nhmrc.gov.au/_files_nhmrc/publications/attachments/r28. pdf (accessed Dec 2013).

35 Aboriginal and Torres Strait Islander Research Agenda Working Group of the National Health and Medical Research Council. Road Map Il: a strategic framework for improving Aboriginal and Torres Strait Islander health through research. Canberra: Commonwealth of Australia, 2010. http:// www.nhmrc.gov.au/files_nhmrc/publications/attachments/r47.pdf (accessed Dec 2013).

36 Leon de la Barra S, Redman S, Eades S, Lonsdale C. A decade of NHMRC People Support expenditure in review: is support for Indigenous health research increasing? Med J Aust 2009; 190: 28-31.

37 National Health and Medical Research Council. NHMRC funded research into Aboriginal and Torres Strait Islander health 2002-2012. Canberra: NHMRC, 2012. http://www.nhmrc.gov.au/_files_nhmrc/ file/grants/dataset/2012/aboriginal_torres_strait_islander_health_ research_2000-2012.xlsx (accessed Jan 2014).

38 Elston JK, Saunders V, Hayes B, et al. Building Indigenous Australian research capacity. Contemp Nurse 2013; 46: 6-12.

39 Australian Institute of Aboriginal and Torres Strait Islander Studies. National Indigenous Research and Knowledges Network. http://www. aiatsis.gov.au/research/nirakn.html (accessed Jun 2014).

40 Brands J. The shape of things to come: visions for the future of Aboriginal and Torres Strait Islander health research. Melbourne: Lowitja Institute, 2014. www.lowitja.org.au/sites/default/files/docs/the-shape-of-thingsto-come.pdf (accessed May 2014).

41 Dwyer J, O'Donnell K, Lavoie J, et al. The overburden report: contracting for Indigenous health services. Darwin: Cooperative Research Centre for Aboriginal Health, 2009. http://www.flinders.edu.au/medicine/ $\mathrm{fms} / \mathrm{sites} /$ health_care_management/documents/Overburden $\% 20$ Report_contracting\%20for\%2OIndigenous\%20Health\%20Services.pdf (accessed Dec 2013)

42 Brands J. Implementation of innovations in Aboriginal and Torres Strait Islander health care. A review of the literature: interim report. Brisbane: Lowitja Institute, 2012 